\title{
Assessment of Factors Affecting Onshore Wind Power Deployment in India
}

\author{
Alok DAS ${ }^{1}$, Hardik K. JANI ${ }^{2 *}$, Surendra Singh KACHHWAHA ${ }^{3}$, Garlapati NAGABABU ${ }^{4}$ \\ ${ }^{1-4}$ School of Technology, Pandit Deendayal Petroleum University, Gandhinagar, Gujarat, India
}

\begin{abstract}
The Present study focuses on the impact of various factors on the growth of wind power generation in seven most wind energy prone states of India, that contain $97 \%$ of India's total wind power potential. The impact of state-wise policy parameters Feed-in Tariff (FIT) rate, Renewable Purchase Obligations (RPO) and Power Purchase Agreement (PPA) are evaluated in terms of aggregate policy indices that indicate the likelihood of wind power deployment in that state, through multivariate statistical analysis. The wind energy technology with reference to wind turbine specific policies, scaling of the project, the impact of hybrid policy, grid-related technological advancements and the improvement of capacity utilization factor (CUF) are discussed. Further, the impact of per capita net domestic product (PCNDP) and power demand-supply scenario are assessed. It was found that these two factors are non-influential on wind power growth. The outcome of the present study is that aggregate policy indices, captive/third party use of feasibility, presence of repowering policy, actual CUF obtained at the location, delay in cash flow and total available power potential are the factors that significantly influence the growth of cumulative installed capacity. This study provides an insight for policymakers for a quantitative assessment of the existing policies along with other factors and assists the project developers to compare and identify suitable locations for wind power projects in the near future. The exchange rate of 1 USD $(\$)=69.38$ INR (₹) has been taken throughout the manuscript.
\end{abstract}

Keywords - Multivariate statistical analysis; policy, power generation; renewable energy, wind energy.

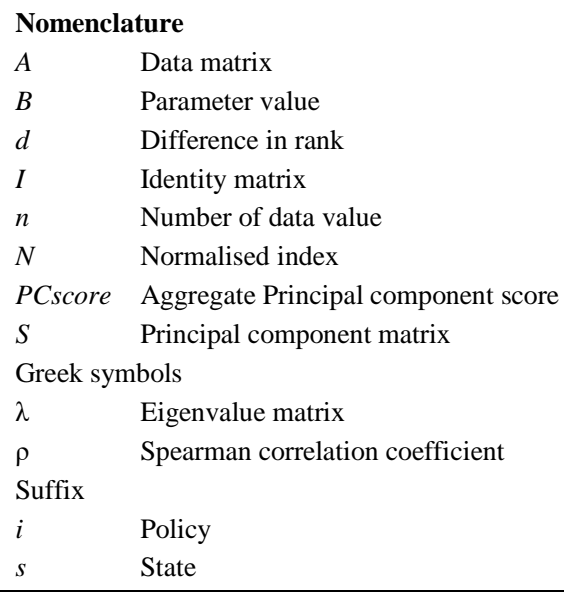

* Corresponding author.

E-mail address: janihardik15@gmail.com 


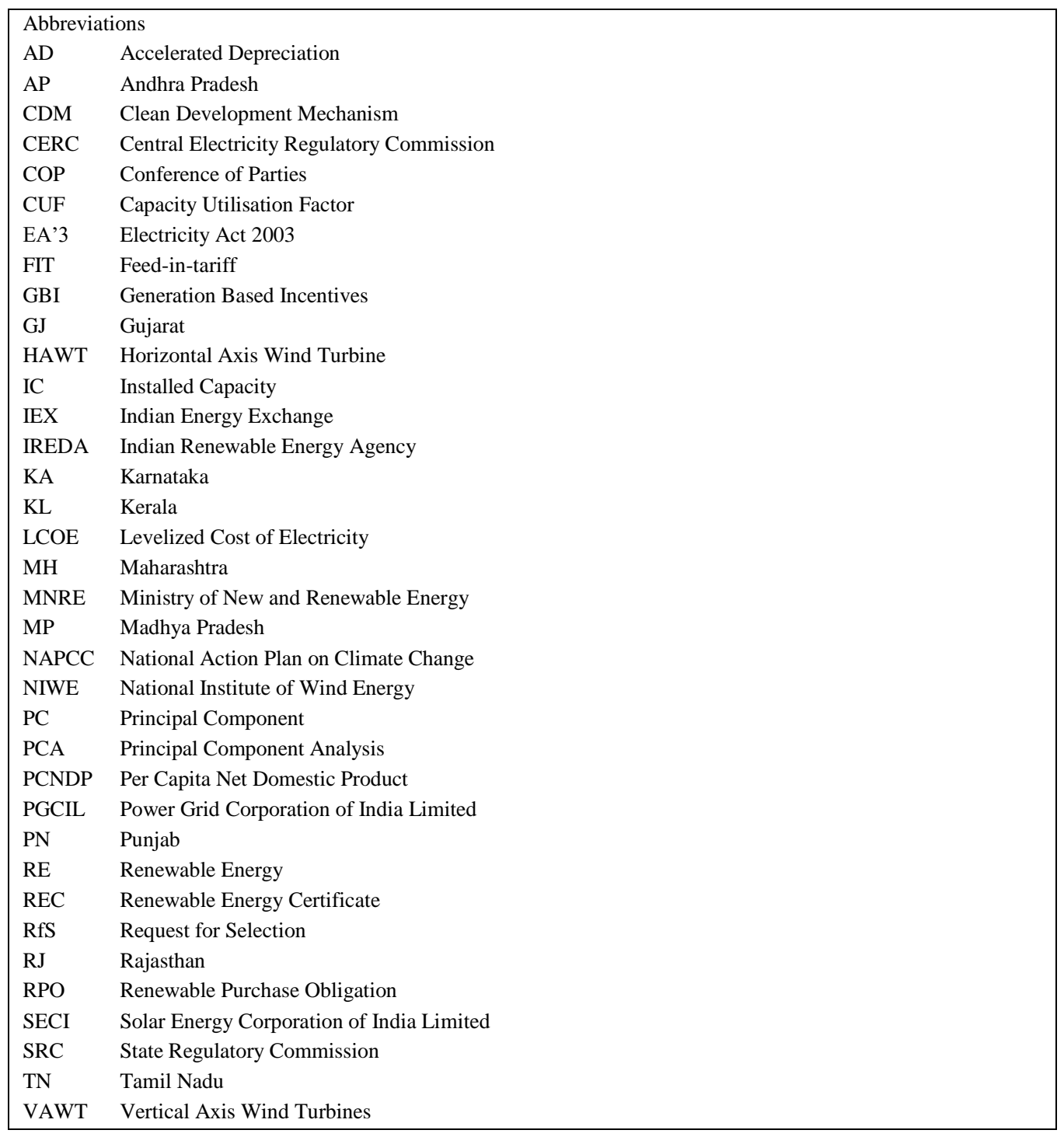

\section{INTRODUCTION}

Policy formation is an intricate process which leads to significant changes at world and national level incorporating regional level implementation [1]. The United Nations is promoting sustainable energy with a focus on having least possible influence on the nature. In order to empower the execution of Clean Development Mechanism (CDM) and Kyoto Protocol for preventing global warming, the Conference of Parties (COP) is organised annually by United Nations in different countries. For promoting the sustainable growth of renewable energy on root level, different energy management strategies have to be formulated in the form of policies (e.g. incentive mechanism, tariff policies etc.) [2]. In this context, India has agreed to shrink the emissions up to 33-35\% from 2005 level and attain around $40 \%$ 
aggregate renewable energy (RE) based power generation by the year 2030 in COP21 summit [3], [4]. Solar-thermal [5]-[7] and biomass energy based applications are extremely promising, however, they demand distinctive application specific system designs and deliver energy output in diverse forms. On the other hand, wind and solar photovoltaic (PV) energy systems are comparatively more generic and have universal designs; being a well-grown industry with high grade energy yields (electrical form); they attract attention of project developers. India is also aiming to achieve $175 \mathrm{GW}(100 \mathrm{GW}$ solar, $60 \mathrm{GW}$ onshore wind, $5 \mathrm{GW}$ offshore wind and $10 \mathrm{GW}$ from other sources) of RE capacity by the year 2022, as per the target set by the Ministry of New and Renewable Energy (MNRE), Government of India [8]. Moreover, the target for Indian offshore wind power capacity of $5 \mathrm{GW}$ by 2022 and $30 \mathrm{GW}$ by 2030 has also been set by MNRE [9]. The boost in Indian onshore wind installed capacity and wind power generation in the last decade has been portrayed in Fig. 1 and Fig. 2, respectively. The wind power installed capacity has exhibited the rise of $25 \mathrm{GW}$ with average annual capacity addition of $2.5 \mathrm{GW}$ (Fig. 1). The electricity generation by means of onshore wind energy in India exhibited the overall growth of $43.28 \mathrm{TWh}$ with an average annual addition of $4.33 \mathrm{GWh}$ (Fig. 2). Here, only onshore wind power generation is depicted due to the non-existence of any offshore wind farm in India till 2018. At the end of year 2018, India's overall RE capacity was nearly $70 \mathrm{GW}$ [8].

At present, unsubsidized renewable power generation is $50 \%$ costlier than non-renewable power generation in India due to the lower capacity utilization factor (CUF), fluctuating power generation, large capital cost and less availability of finance [10]. Therefore, the continuous growth of RE generation needs the support of steady and effective policy backing. Furthermore, it has been found that the effective RE policies can reduce the emissions and lead to a stable economic growth [11]. Recently, MNRE has announced National Wind-Solar Hybrid Policy to hybridize wind and solar power sectors [8]. Hybridization involves repowering of the existing project as well as the deployment of new ones. For aiming to achieve the aforementioned target, hybridization of wind and solar power projects is an important step as it optimizes the use of both the resources at a lower overall project cost.

Renewable energy policies have played an important role for the development of wind power in India in the last three decades. The evolution of Indian wind energy policy since 1987 is illustrated in Table 1. Indian RE generation program gained serious attention in the late 1990s, but the significant growth initiated only after the formation of the Electricity Act 2003 (EA'03), National Electricity Policy 2005 and National Tariff Policy 2006. According to the EA'03 and National Electricity Policy 2005, the central government formed national policies in association with the state governments and permitted the deployment of standalone power generation systems based on renewable energy sources [12], [13]. The declaration to achieve Renewable Purchase Obligation (RPO) for wind power is $15 \%$ from wind power by the year 2020 was made in 2008. In the same year, PGCIL (Power Grid Corporation of India Limited) was established for governing and monitoring the penetration of electrical power grid across the nation. The provision of giving generation-based incentives (GBI) to the power developers and Feed-in Tariff (FIT) rate agreement were formulated in 2009. GBI and FIT were later withdrawn in 2012 and later reintroduced in 2013 with updated norms (Table 1). In the year 2014, the Accelerated Depreciation (AD) allowance was reduced to $40 \%$ compared to the earlier limit of $80 \%$. India has a central, as well as state-specific policy structure. The policies like AD, GBI and Tax benefits are developed by Central Electricity Regulatory Commission (CERC) and implemented uniformly throughout the country, whereas policies like FIT rate, Power Purchase Agreement (PPA) duration, RPO and captive user policy are state specific and governed by State Regulatory Commissions (SRCs). 
TABLE 1. Wind POWER POLICY EVOLUTION (1987 TO 2018) IN INDIA

\begin{tabular}{|c|c|}
\hline Year & Wind Power \\
\hline 1987 & Establishment of Indian Renewable Energy Agency (IREDA) as a public financing organization \\
\hline 1989 & Wind project financing by IREDA \\
\hline 1990 & Accelerated Depreciation (AD) policy introduced (100\% depreciation for the first year) [14] \\
\hline 1991 & $\begin{array}{l}\text { The Electricity Laws Act amended for private sector participation; licensing agreement with } \\
\text { international wind companies }\end{array}$ \\
\hline 1993 & $\begin{array}{l}\text { Wind turbine exemption from Excise duty \& Sales tax; reduced import duties on wind turbine } \\
\text { components (rotor blades); Issuance of state wind power procurement guidelines }\end{array}$ \\
\hline 1995 & Turbine approval and certification guidelines declared \\
\hline 2002 & $\begin{array}{l}\text { AD reduced to } 80 \% \text { [14]; Income tax exemption/Tax holiday policy announced; Excise (diminished } \\
\text { from } 8.5 \% \text { to } 0 \% \text { ) and Custom duty (cutback by } 2.5 \%-5 \% \text { ) benefits declared [15]; (complete } \\
\text { exemption of rotors and wind turbine controllers from the excise tax [15]) }\end{array}$ \\
\hline 2003 & $\begin{array}{l}\text { The Electricity Act (EA’03) implemented, which demanded the establishment of wind professional } \\
\text { tariff }\end{array}$ \\
\hline 2004 & First Renewable Purchase Obligation (RPO) policy launched in Maharashtra state \\
\hline 2005 & $\begin{array}{l}\text { Entry of Indian wind projects into Clean Development Mechanism (CDM) market to earn Certified } \\
\text { Emission Reductions (CERs) }\end{array}$ \\
\hline 2006 & $\begin{array}{l}\text { National Tariff Policy announced, which defined the minimum amount of tariff to be paid in different } \\
\text { sectors. Later it mandated State Regulatory Commissions to fix RPOs. }\end{array}$ \\
\hline 2008 & $\begin{array}{l}\text { First National Action Plan on Climate Change (NAPCC) established (RPO share envisioned at } 15 \% \\
\text { by 2020); open Access regulations; IEX (Indian Energy Exchange) and PGCIL (Power Grid } \\
\text { Corporation of India Limited) founded }\end{array}$ \\
\hline 2009 & Generation Based Incentives (GBI) announced; Feed-In Tariff (FIT) declared \\
\hline 2010 & $\begin{array}{l}\text { Central Electricity Regulatory Commission (CERC) guidelines for Renewable Energy Certificates } \\
\text { (RECs) announced; FIT revised }\end{array}$ \\
\hline 2011 & $\begin{array}{l}\text { National Clean Energy Fund (NCEF) and Renewable Regulatory Fund (RRF) introduced; REC trading } \\
\text { initiated in IEX \& PGCIL; Assessment of investment climate for wind power development [1] }\end{array}$ \\
\hline 2012 & Withdrawal of $\mathrm{AD}$ and GBI \\
\hline 2013 & $\begin{array}{l}\text { GBI reinstated }(₹ 0.5 / \mathrm{kWh}(\$ 0.0072 / \mathrm{kWh}) \text { additional payment above FIT, subject to cumulative of ₹10 } \\
\text { million/MW ( } \$ 0.14 \text { million/MW) of installed capacity; low-cost financing introduced; RRF made } \\
\text { effective after being deferred on previous two occasions; Income tax exemption/Tax holiday policy } \\
\text { expired }\end{array}$ \\
\hline 2014 & AD reinstated with $40 \%$ (in the first year); Operational guideline for AD declared by IREDA [17] \\
\hline 2015 & $\begin{array}{l}\text { Revised operational guideline for GBI declared by IREDA [18]; National offshore Wind Energy policy } \\
\text { announced by MNRE [19] }\end{array}$ \\
\hline 2016 & Formation of Wind-Solar Hybrid Policy draft by MNRE [20] \\
\hline \multirow[t]{2}{*}{2017} & $\mathrm{AD}$ reduced to $40 \%$ (in the first year); \\
\hline & $\begin{array}{l}\text { Scheme for setting up of } 1000 \text { MW Inter-State Transmission System connected Wind power projects } \\
\text { [21]; } \\
\text { Guideline for Tariff based Bidding Process declared [22] }\end{array}$ \\
\hline 2018 & $\begin{array}{l}\text { Ministry of Power proposed to remove REC in the proposed tariff policy [23]; } \\
\text { Offshore wind power installation capacity targets fixed by MNRE [9]; } \\
\text { Ministry of Power recommended to remove REC in the proposed tariff policy [23]; } \\
\text { Declaration of Wind-Solar Hybrid Policy by MNRE [8]. }\end{array}$ \\
\hline
\end{tabular}




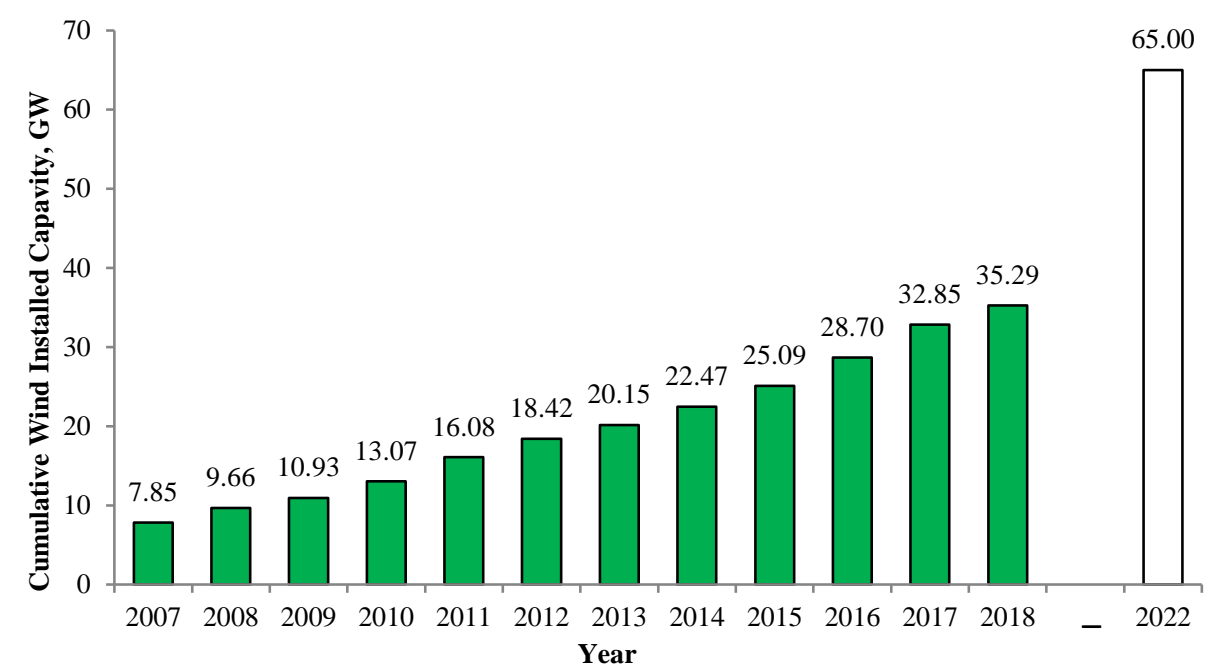

Fig. 1. Cumulative wind power installed capacity in India over the years (2007-2018) and the year 2022 target [24], [25].

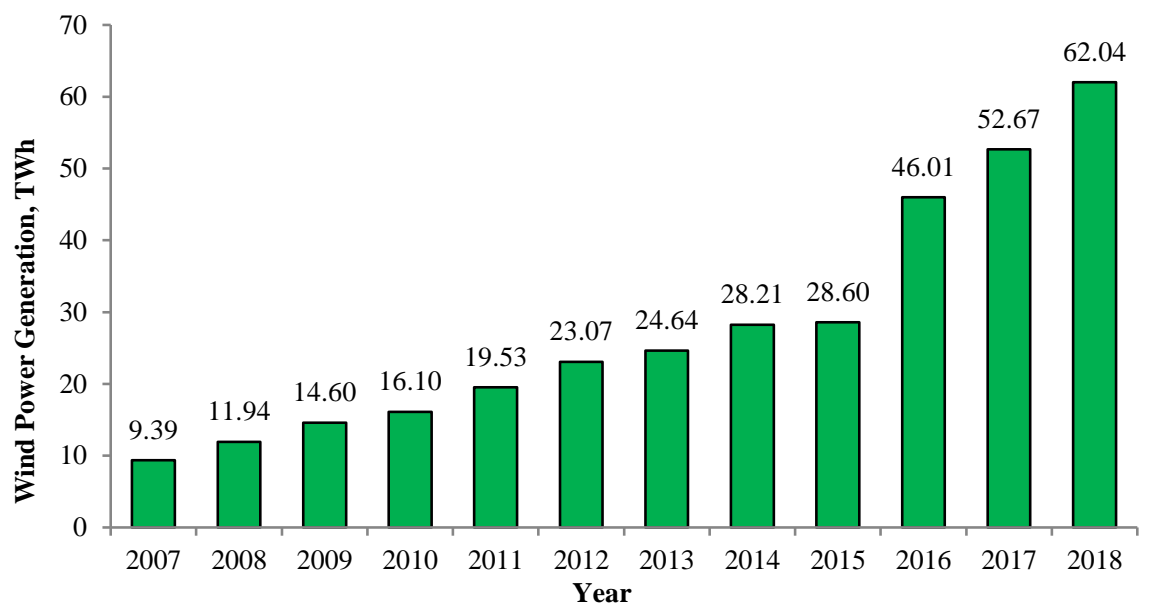

Fig. 2. Annual wind power generation in India over the years (2007-2018) [24], [25].

A comprehensive study on energy policies [26] in BRICS countries (Brazil, Russia, India, China and South Africa) concluded that there is an urgent need for redefining the energy policies considering the geographical, financial, environmental and societal scenarios. Hence, the policy scenario significantly influences the growth of wind power generation. At present, there are very limited numbers of studies that have been performed in a quantitative manner to analyze renewable energy policies in India (refer to Table 2). Jagadeesh [27] conducted a case study on the Indian states (Tamil Nadu and Andhra Pradesh), in order to identify ways for boosting the wind power generation, considering commercial, technical, business and organizational obstacles. The study suggested continuing with the incentive based policies like accelerated depreciation, tax holidays, excise and custom duty exemption for the self-sustainability of ongoing wind projects. Benecke [28] performed an elaborative 
investigation on the impact of state wind energy policy elements, such as the tariff rate and its increment, contract duration, Renewable Portfolio Standards (RPS) limits, wheeling charges and banking facility in reference to the installed capacity and private investment in Kerala and Tamil Nadu states of India. The study found out that the availability of land is important but does not drive investment decisions; and the policy conditions need to be certain, stable and predictable for attracting more private investments. Usha Rao et al. [29] executed a study for four wind prone states of India (Andhra Pradesh, Gujarat, Tamil Nadu and Maharashtra) using the Bass model (mixed influence model) and concluded that the wind potential diffusion rate (conversion of potential in to installed capacity) ranges from $16 \%$ (lowest in Gujarat) to $100 \%$ (highest in Tamil Nadu).

In an attempt to identify the impact of state and national policies, Schmid [30] investigated the growth of RE capacity for Indian states and their contribution to the total capacity. The analysis concluded that there is no significant correlation between the preferential FIT policy and the deployment of RE power due to policy inconsistency and the absence of competition in the wind power sector. Kathuria et al. [31] assessed the influence of state policies on the Foreign Direct Investment (FDI) for wind power generation across the states of India and concluded that the policy indices of the parameters (FIT, open access transmissions, Captive/third party use, wheeling and banking charges) are directly proportional to the FDI. Sangroya et al. [32] analyzed the impact of a state-wise incentive policy on wind energy sector and concluded that the states with captive usage allowance and FIT benefits are more influential in the development of wind power capacity. However, the study did not consider the quantification of the incentives and, consequently, was not able to evaluate the impact of different rates of FIT. Besides these drawbacks, the study excluded the influence of third party sale on wind power sector.

A recent study compared the state-specific policy scenarios for seven windiest states of India [33] by applying a principal component analysis (PCA) under multivariate statistical approach. The influential parameters (FIT, PPA duration, RPO target and wheeling charges) are used as an input [14]. Here, the study has incorporated the combined input of FIT and wheeling charges policy. However, according to their applications being specific in selling and captive purpose respectively, these policies have to be analysed separately. Therefore, due to this limitation, calculated policy indices cannot be adopted as the true indicators to compare and analyse the deployment scenario of wind power in respective states. The analysis confirmed the importance of state policies for the growth of wind power generation. The study also pointed out that higher power potential and Per Capita Net Domestic Product (PCNDP) were directly proportional to wind power growth (for the duration from 1993 to 2012); whereas the power deficiency factor had no impact on wind power growth.

The statistical analyses are categorized in two approaches as univariate and multivariate. As the name suggests the univariate analysis deals with one variable only, whereas the multivariate statistical analysis is used for the identification of combined effects of multiple variables. In case where the data is in counting form, available count data models like Poisson model, negative binomial model, Hurdle or two-part models and zero-inflated models are utilized [34]. Owing to the irregular distribution of count data models, in the empirical analysis conducted in previous literature the Poisson regression model and negative binomial fixed effect regression model were mostly used [35]. The regression models can be used for univariate analysis only. For multiple interrelated variables, multivariate approach is essential. There are different types of methods available for multivariate statistical analysis, like principal component analysis (PCA) [14], factor analysis, fixed-random effect analysis [32] and Bass model (mixed influence model) [29]. In Bass model, the weights of different 
parameters have to be assigned as input which requires additional data and knowledge. In fixed and random effect analysis the weightage of each variable is calculated in the polynomial form which gets complex while dealing with large number of variables [32]. As compared to this, the PCA has more rational approach, since the weightage distribution (based on Eigen value) is calculated rather than giving fixed weightages. Moreover, PCA converts larger-dimension data into a single dimension index [36]. Hence, PCA is identified as the simplest yet reliable technique to study the combined impact of multiple correlated variables.

Literature survey indicates that state policies like AD, GBI, PPA duration, RPO target and wheeling charges significantly influence the growth of wind power generation. Compared to the past studies, the present study has many differences. Due to the continuously changing financial scenarios, availability of resources (land and transmission system) and technological advancements, there is an urgent need to update and evaluate the existing policy structure in Indian scenario. Moreover, due to different industrial applications, the FIT and captive use policies should be assessed in an independent manner, which is the main focus and novelty of present study and fills the existing research gap in the policy analysis. Few studies have conducted the comparative analysis without considering the impact of third party sale and the quantification of tariff policies [32]. All these drawbacks have been eliminated in the present study by considering the quantified FIT data. Furthermore, the influence of the regional policy from the technology point of view has also been investigated, which was never done before.

The core aim of the present study is the assessment of factors that affect onshore wind power deployment in India. For this purpose, seven most wind energy prone states of India (as identified by MNRE [33]) have been considered. Data and methodology used for calculation of policy indices using principal component analysis and further study has been described in Section 2. Section 3 consists of the study on various factors affecting the wind power deployment in India. Section 4 gives an overall discussion on the status of state-wise wind power deployment and the conclusions are summarized in Section 5. The results indicate that the state-specific policy index is significant for wind in attracting installed capacity. The present study will be beneficial to the policy-makers to establish and follow a consistent policy framework to achieve the target of wind power deployment, as well as to project developers to identify the suitable location to invest in new power projects.

\section{Data AND Methodology}

Various factors affecting the wind power deployment in India such as wind energy policies, captive/third party utilization and repowering policy, wind energy technologies, available wind power potential and other influential factors are shown in Fig. 3. Wind energy policies for the parameters FIT rate, PPA duration and RPO target vary with states, as different states have their own state-specific policies. Government of India has identified seven states, namely, Maharashtra (MH), Karnataka (KA), Gujarat (GJ), Rajasthan (RJ), Tamil Nadu (TN), Madhya Pradesh (MP) and Andhra Pradesh (AP) as the wind energy prone states [33]. Moreover, these seven states have total wind power potential of $292.97 \mathrm{GW}$ which is $96.93 \%$ of India's total wind power potential (302.25 GW) [33]. Due to this significant wind potential, respective state governments have formed their own specific wind energy policies. Other states of India do not have specific wind energy policy due to lower wind potential and therefore, not incorporated in the study. Recent actual data of considered variables (FIT rate, PPA duration and RPO target for the seven states of India) has been used for the study and presented in Table 3. 


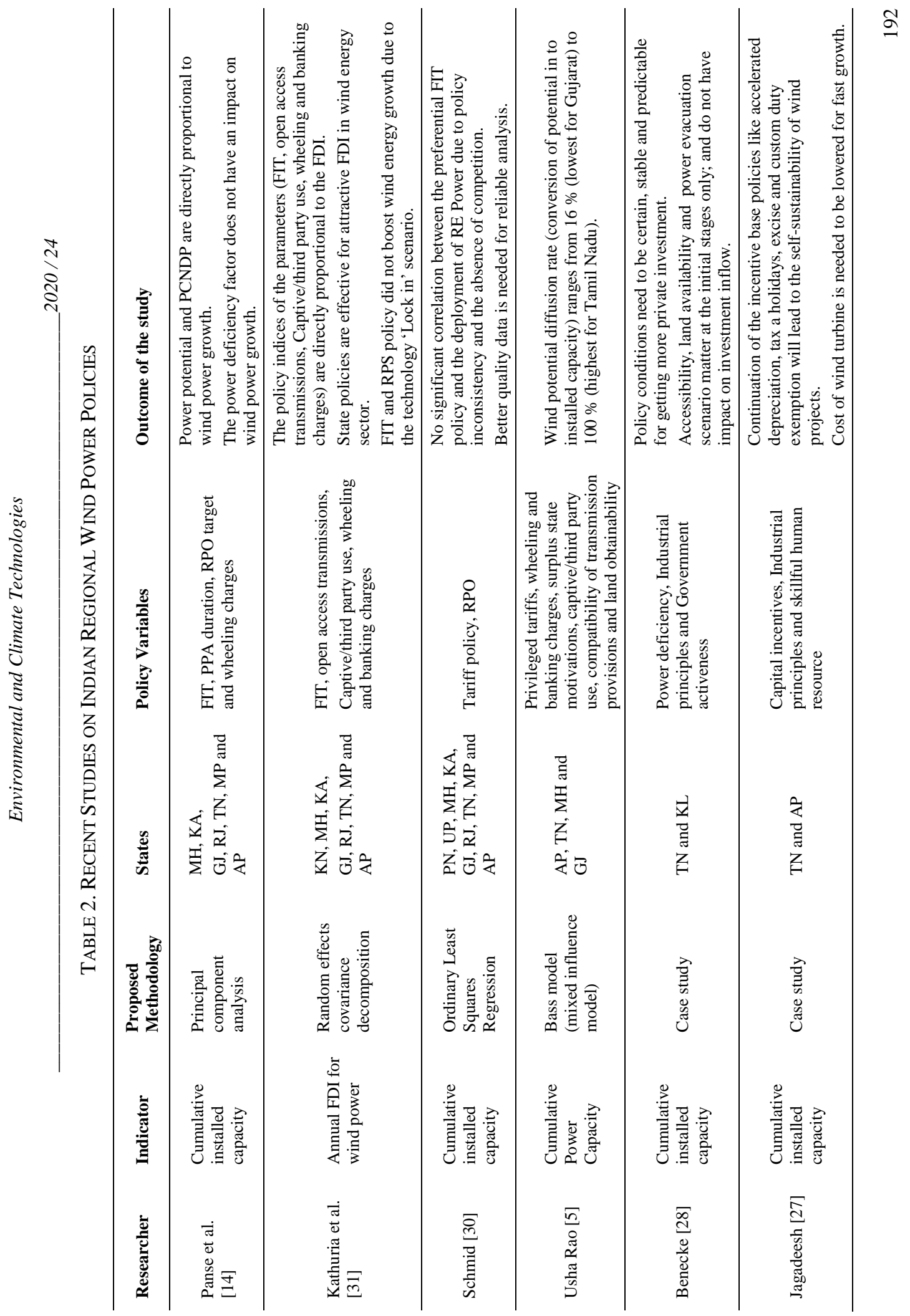


In order to evaluate the comparative scenario and the likelihood of wind power deployment considering all the three variables (FIT rate, PPA duration and RPO target), multivariate approach has been applied. Among the different multivariate statistical analysis methods, PCA has been identified as reliable and effective [14] to calculate aggregate policy indices representing the combined effect of considered policy variable of seven states (refer to Section 3.1). Methodology for the multivariate statistical analysis performed on the state-wise wind energy policy data is elaborated in Section 2.1.

The captive/third party utilization policy has been excluded from the multivariate analysis and discussed separately due to the discrete industrial applications [37]. FIT policy is applicable when selling the generated power to the local distribution company, whereas in a third party sale, the generated power is sold to the third party/captive user situated near or far away from the location of power generation. Present scenario of state-wise captive and repowering policy has been given in Section 3.2. Policy provisions based on the scale and type of wind energy technology along with the available wind power potential have been discussed in Section 3.3. Other probable factors, such as PCNDP and power generation scenario with present installed capacity, have been further discussed in Section 3.4.

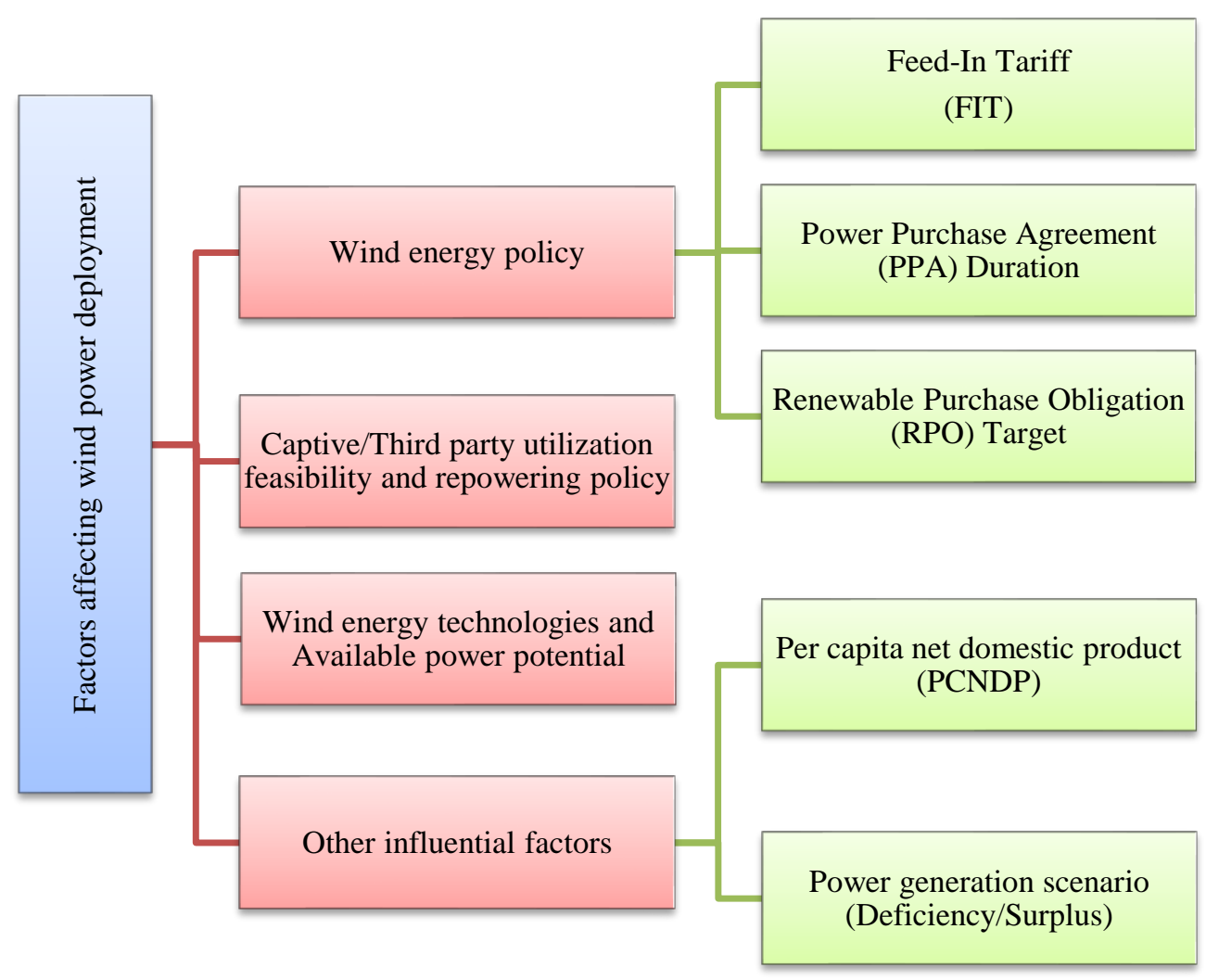

Fig. 3. Various factors affecting the wind power deployment. 


\subsection{Methodology for multivariate statistical analysis}

The policy data used for the multivariate statistical analysis contains three policy variables: FIT rate, PPA duration and RPO target. The FIT rate indicates the tariff rate at which the power developers are paid for generating the power. The PPA duration is the time period for which the power purchase agreement is defined. The RPO target is the minimum fraction of power that should be generated through renewable energy. In order to identify the relation among the considered variables, the input data is first normalized (Table 3 ) and the correlation coefficients (Table 4) are computed. If the study variables are found to have significant correlation, the Principal Component Analysis (PCA) is performed. The eigenvalues, eigenvectors and principal components (Table 5, Table 6 and Table 7, respectively) and the aggregate principal component (PC) scores are computed. The methodology has been elaborated exhaustively in the following subsections. Here, the computation of the correlation coefficients and principal component analysis are performed using multivariate analysis tools of Minitab 17.1.0 software.

\subsubsection{State-wise Policy Normalisation}

The data of three policy variables FIT, PPA duration and RPO target are shown in Table 3. All three policy variables FIT, PPA duration and RPO target are of different range and units. These data are converted to a normalized matrix using the min-max criterion technique. The general expression for the min-max criterion is given as follows [14],

$$
N_{i s}=\frac{B_{i s, \text { actual }}-B_{i s, \text { min }}}{B_{i s, \text { max }}-B_{i s, \text { min }}},
$$

where $N_{i s}$ normalized index of $i^{\text {th }}$ policy for $s^{\text {th }}$ state; and $B_{i s}$ stands for the parameter value of policy $i$ for state $s$.

Equation (1) gives a higher index for the higher data value, which means the data with the highest value is assigned as the index of 1 and the lowest as 0 . Here, the higher value is not always desirable for every parameter. For parameters FIT, PPA duration and RPO target higher values are desirable for the growth of wind power generation, whereas for the variable like wheeling charges lower value is beneficial for the growth, hence Equation (1) cannot be used directly. In order to apply Equation (1) in a generalized manner, the min-max criteria is replaced by the best-worst criteria as presented in Equation (1),

$$
N_{i s}=\frac{B i s, \text { actual }-B i s, \text { worst }}{B i s, \text { best }-B i \text { s,worst }},
$$

where $B_{i s}$ and $N_{i s}$ represent the same parameters as in Equation (1), the suffix best stands for most desirable value and suffix worst stands for least desirable value. Table 3 reflects the normalised values of state specific parameters.

\subsubsection{State-wise Policy Correlation Matrix}

The normalized matrix obtained through Equation (2) exhibits the relative measure of the status of state for specific policies. The Spearman correlation technique That has monotonic function is applied to determine the relationship among policy variables [38]. The standard expression to calculate the Spearman correlation coefficient ( $\rho)$ is given by Equation (3) [38], 


$$
\rho=1-\frac{6 \sum d_{i}^{2}}{n\left(n^{2}-1\right)},
$$

where $d_{i}$ is the difference in the rank of $i^{\text {th }}$ dataset and $n$ is the number of datasets (here, $n=7$ ).

Spearman correlation reverts a value from -1 to +1 [38], where, $+1,-1$ and zero value indicate exact $+v e$ correlation, exact - ve correlation and no correlation respectively. The $p$-value obtained in the process represents the probability of finding the present result if the correlation coefficient stayed zero. If the probability value is less than $5 \%(\mathrm{p}<0.05)$, the correlation is termed as statistically significant.

\subsubsection{Principal Component Analysis}

PCA is a mathematical procedure that transforms a number of possibly correlated variables into a (smaller) number of uncorrelated variables called principal components (PC) [39]. PCA is one of the most influential multivariate approaches used for data analysis [36]. PCA simplifies the high dimensional data by reducing the complexity while keeping the trends and patterns intact [36]. The PCA transforms the data into fewer dimensions, which leads to the features' summarization [36]. The eigenvalues, eigenvectors and principal components are computed by means of the PCA from the correlation data matrix. The characteristic equation for determination of eigenvalue can be given as [40]:

$$
\operatorname{Det}(A-\lambda I)=0 \text {, }
$$

where

$A \quad$ the raw data matrix (Table 3);

I the identity matrix;

$\lambda \quad$ the eigenvalue matrix (refer to Table 5).

The eigenvectors can be derived from the following equation [40], where $X$ is the eigenvector matrix (refer to Table 6).

$$
(A-\lambda I) X=0
$$

The sum of the eigenvalues is always equal to the number of variables. The eigenvalue represents the relative amount of information contained by the principal component. The eigenvalues are used to determine how many PCs to retain based on their proportion [41]. Here, all the PCs are considered for further study. Now, the principal components (also termed as factor loadings or the standardised score) matrix $(S)$ can be derived from the data matrix $(A)$ and the eigenvector matrix $(X)$.

$$
S=A X
$$

The standardised score matrix $S$ (refer to Table 7) and the eigenvector matrix $X$ will be further utilised for the derivation of aggregate principal component score (aggregate indices) as described below.

\subsubsection{Aggregate Principal Component Scores}

The aggregate principal component scores or the policy indices are the collective scores of each case (row) on each factor (column) [39]. For computing the PC score for a given case and a given factor, one takes the case's standardized score (PC given in Table 7) on each variable factor, multiplies by the corresponding factor loading (eigenvector given in Table 6) 
of the variable for the given factor and sums the products [39]. The PC score for any particular state can be derived from the following equation,

$$
\text { Pscores }=\sum_{v=1}^{n}\left(\sum_{v=1}^{n} X_{i} S_{i}\right),
$$

where

PCscores $_{\text {S }}$ the PC score for a particular state;

$X_{i} \quad$ corresponding eigenvector (factor loading of the variable);

$S_{i} \quad$ corresponding principal component (standardized score of the case);

$i \quad$ the number of component and $v$ is the policy variable number.

\section{Various Factors Affecting Wind Power Deployment}

Different factors that influence the growth of wind power in India has been studied (Fig. 3). The study includes state-level wind energy policies, captive/third party utilisation policy and repowering policy along with the policy provisions based on wind energy technologies. The other possible factors (PCNDP and power generation surplus/deficiency scenario) that may influence the growth of wind power generation have been discussed.

\subsection{Wind Energy Policy Analysis}

Multivariate statistical analysis on policy variables has been performed for the derivation of aggregate policy indices for each considered state. The aggregate indices or the principal component scores of different states are the indicators of the influence of overall policy scenario on the growth of installed capacity in these states. Using the step by step implementation of the methodology elaborated in the prior section and the data shown in Table 3, the aggregate policy indices for all the seven states have been derived by incorporating the FIT, PPA duration and RPO target policies.

\subsubsection{State-wise policy normalisation}

In the present case, the min-max normalization can be implemented with reference to the current minimum and maximum values of the considered states. The input data matrix given in Table 3 is normalized by the best-worst criterion approach expressed by Equation (2). RJ exhibits highest FIT rate (₹5.74 kWh $=\$ 0.083 \mathrm{kWh}$ ) among the considered states. Hence, the normalized value determined for FIT policy is 1.00 for RJ. On the other hand, TN has the least FIT rate (₹4.16 $\mathrm{kWh}=\$ 0.06 \mathrm{kWh}$ ) therefore the obtained normalized value is equal to zero. Similarly, GJ, RJ, MP and AP show the highest duration of PPA (25 years) which is equivalent to the normalized value of 1.00. The normalized value is zero for lowest PPA duration value of MH (13 years). KA and AP offer maximum and minimum RPO target of $11 \%$ and $4.75 \%$, which correspond to the normalized values of one and zero, respectively. 
TABle 3. Current Status of State-Wise Wind Power Policies ANd Corresponding INDICES CALCULATED THROUGH NORMALISATION

\begin{tabular}{|c|c|c|c|c|c|c|}
\hline \multirow[b]{2}{*}{ State } & \multicolumn{3}{|c|}{ Actual values (Input data) } & \multicolumn{3}{|c|}{ Normalized values } \\
\hline & $\begin{array}{l}\text { FIT rate, } \\
₹ / k W h\end{array}$ & $\begin{array}{l}\text { PPA } \\
\text { duration, } \\
\text { years }\end{array}$ & $\begin{array}{l}\text { RPO } \\
\text { Target, \% }\end{array}$ & FIT & $\begin{array}{l}\text { PPA } \\
\text { duration }\end{array}$ & $\begin{array}{l}\text { RPO } \\
\text { target }\end{array}$ \\
\hline Maharashtra (MH) & 5.56 & 13 & 10 & 0.89 & 0.00 & 0.84 \\
\hline Karnataka (KA) & 4.5 & 20 & 11 & 0.22 & 0.58 & 1.00 \\
\hline Gujarat (GJ) & 4.19 & 25 & 8.25 & 0.02 & 1.00 & 0.56 \\
\hline Rajasthan (RJ) & 5.74 & 25 & 8.9 & 1.00 & 1.00 & 0.66 \\
\hline Tamil Nadu (TN) & 4.16 & 20 & 9 & 0.00 & 0.58 & 0.68 \\
\hline Madhya Pradesh (MP) & 4.78 & 25 & 6.05 & 0.39 & 1.00 & 0.21 \\
\hline Andhra Pradesh (AP) & 4.84 & 25 & 4.75 & 0.43 & 1.00 & 0.00 \\
\hline
\end{tabular}

\subsubsection{Policy correlation matrix}

The Spearman correlation matrix with correlation coefficients and the probability values is computed from input data matrix (Table 3). As it can be seen from Table 4, FIT is has a nominal correlation with PPA duration $(0.12)$ and RPO target $(-0.11)$. However, these two policies are highly correlated with each other with the correlation coefficient of -0.84 . PPA duration and RPO target indicates a significant correlation ( $p$-value (0.02) less than 0.05), whereas the correlation of FIT with the remaining two variables are found to be non-significant ( $p$-value of 0.12 and -0.11 , respectively). Here, the negative correlation implies to the inverse proportionality, which means the states with higher RPO target are proposing shorter PPA duration. Such scenario is beneficial for the state governments as they can update the PPA terms after the completion of existing duration as per the requirement. However, the low PPA duration shrinks the developers' security and also affects the financial factors of the project, which influences the FIT rate at which they would have been comfortable to sell the power.

TABLE 4. SPEARMAn CORRELATION MATRIX FOR STATE Policy INDICES

\begin{tabular}{llll}
\hline Variable & FIT & PPA duration & RPO target \\
\hline \multirow{2}{*}{ FIT } & 1.00 & & \\
& $(0.00)$ & & \\
PPA duration & 0.12 & 1.00 & \\
& $(0.80)$ & $(0.00)$ & 1.00 \\
RPO Target & -0.11 & -0.84 & $(0.00)$ \\
\hline
\end{tabular}

Note: The figures in parenthesis indicate p-values (probability values).

\subsubsection{Principal component analysis}

After identifying the correlation among the considered policies, the PCA has been executed using the data matrix (Table 3) and the eigenvalues, eigenvectors and the principal components are computed as shown in Table 5, Table 6 and Table 7, respectively. Here, the eigenvalue of PC1 is 1.6954 and the total number of parameters is three; which implies that 
PC1 comprises $56.51 \%$ of the total information contained by all the PCs. Similarly, the eigenvalue of PC2 is 0.9585 , which is $31.95 \%$ of the total information. Normally, all the PCs are not incorporated as the trailing components involve the majority of the variance [36]. PC1 and PC2 cumulatively contain $88.46 \%$ of total information. Therefore, PC3 can be neglected due to its minimal share $(11.54 \%)$ while computing the PC scores. However, from accuracy point of view, all 3 PCs are used for further study.

TABLE 5. EIGENVALUE AND ITS PROPORTION OF POLICY INDICES

\begin{tabular}{llll}
\hline Component & Eigenvalue & Proportion & Cumulative \\
\hline PC1 & 1.6954 & $56.51 \%$ & $56.51 \%$ \\
PC2 & 0.9585 & $31.95 \%$ & $88.46 \%$ \\
PC3 & 0.3461 & $11.54 \%$ & $100.00 \%$ \\
\hline
\end{tabular}

TABLE 6. EIGENVECTORS OF STATE POLICY INDICES

\begin{tabular}{llll}
\hline Features & PC1 & PC2 & PC3 \\
\hline FIT & 0.2894 & -0.9398 & -0.1818 \\
PPA duration & -0.6943 & -0.0753 & -0.7157 \\
RPO Target & 0.6589 & 0.3334 & -0.6743 \\
\hline
\end{tabular}

TABLE 7. PRINCIPAL COMPONENTS OF STATE POLICY INDICES

\begin{tabular}{llll}
\hline State & PC1 & PC2 & PC3 \\
\hline MH & 2.2084 & -0.7006 & 0.6443 \\
KA & 0.9521 & 0.9345 & -0.4531 \\
GJ & -0.7815 & 0.9001 & -0.2993 \\
RJ & 0.1341 & -1.3379 & -0.9519 \\
TN & 0.1916 & 1.1423 & 0.2627 \\
MP & -1.1704 & -0.3249 & 0.2070 \\
AP & -1.5342 & -0.6135 & 0.5903 \\
\hline
\end{tabular}

\subsubsection{Aggregate policy indices (PC scores)}

The eigenvectors for each principal component corresponding to the respective policies are exhibited in Table 6 and the principal components corresponding to each state are presented in Table 7. The aggregate policy index (PC score) is calculated by systematic multiplication of these two matrices and the product is presented in Fig. 4, which depicts the value of the PC score for each policy and aggregate policy index corresponding to all seven states. $\mathrm{MH}$, KA and RJ states have positive aggregate policy indices (RJ having the highest value) which represent favourable policy environment for the deployment of wind power. Whereas, GJ, TN, MP and AP states are exhibiting the negative aggregate policy indices (TN having the least value of -1.1430) which represents the less favourable policy structure as compared to other considered states. The results can be interpreted as states with a lower growth and/or lower wind power potential propose a more attractive policy structure (especially RJ with a maximum index of 2.4423); and the states (especially GJ and TN) with healthy resources (techno-economic as well as energy potential) propose a comparatively strict policy scenario. Whereas, KA is proposing a sound policy support (index of 0.317 ) in spite of considerable power potential, thus, a more preferable choice among other states. 
In order to examine the sensitivity of the aggregate policy indices shown in Fig. 4, the two states that have maximum and minimum policy index values were selected. In the present study, states RJ and TN have the maximum and minimum policy index values of 2.4423 and -1.1430 respectively. As discussed in Section 2.1.1, the higher values of the policy variables are desirable for a faster growth of wind power sector. This implies that the increment in the policy input values would increase the aggregate policy index and vice versa. The sensitivity analysis has been done for two cases. In the first case, the policy variables (FIT rate, PPA duration and RPO target) for state RJ were decreased by $5 \%$, whereas in the second case, the same policy variables for TN were increased by $5 \%$. The sensitivity analysis gives information about the comparative change in policy index values of the states by diminishing policy variables of the specific state with the highest policy index and boosting the policy variables of the specific state with the least value of policy index.

The result of sensitivity analysis is summarized in Table 8 . In both cases the percentage variation in the policy indices of the states is less than $1 \%$, except $\mathrm{MH}$, which have the variation of $8.95 \%$ and $-3.03 \%$ in case 1 and case 2 , respectively. It can be observed that the decrement in policy variable values of RJ changes the aggregate index values of states however, does not change the relative scenario of the states (Case 1,Table 8). RJ remains the state with highest policy index and the other states follow the same relative trend as the current scenario. Moreover, the increment in policy variable values of TN changes the aggregated index values and also alters the comparative scenario of the states (refer to Case 2 in Table 8). Due to this, TN rises to the second least index value, whereas the state GJ has the least policy index. This indicates that a state can improve its aggregate policy index and hence, the growth of wind power by means of amendments in policy variables in appropriate direction. The other factors affecting the deployment of wind power sector are elaborated in Section 4.

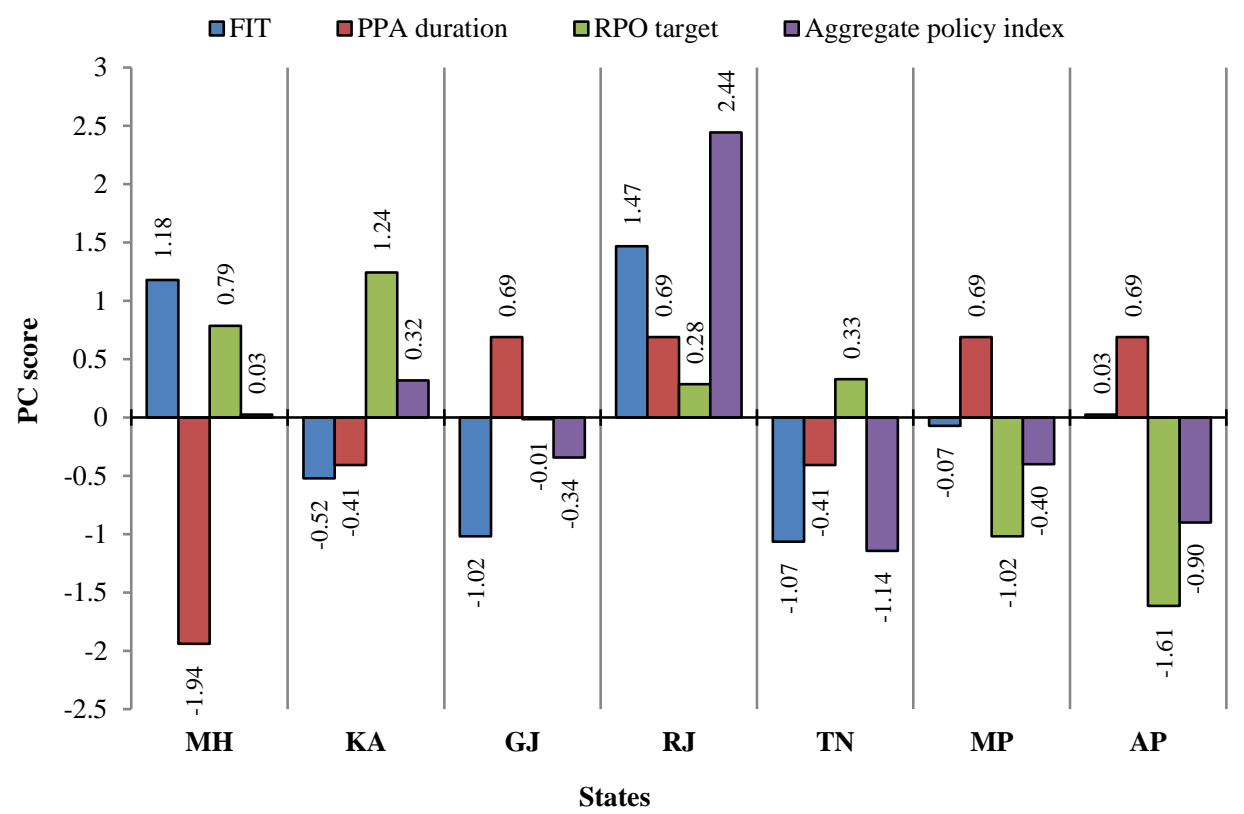

Fig. 4. PC Scores of each considered policy for each state [Source: authors'own computation]. 
TABLE 8. SENSITIVITY ANALYSIS OF AgGREGATE POLICY INDICES

\begin{tabular}{llllll}
\hline \multirow{2}{*}{ State } & Current scenario & Case 1* & \multicolumn{3}{c}{ Case 2** } \\
\cline { 2 - 6 } & Policy indices & Policy indices & \% variation & Policy indices & \% variation \\
\hline MH & 0.0260 & 0.2586 & 8.95 & -0.0529 & -3.03 \\
KA & 0.3170 & 0.3973 & 0.25 & 0.1541 & -0.51 \\
GJ & -0.3418 & -0.2978 & -0.13 & -0.5022 & 0.47 \\
RJ & 2.4423 & 1.7733 & -0.27 & 2.4173 & -0.01 \\
TN & -1.1430 & -1.1321 & -0.01 & -0.5432 & -0.52 \\
MP & -0.4012 & -0.2542 & -0.37 & -0.4943 & 0.23 \\
AP & -0.8994 & -0.7452 & -0.17 & -0.9788 & 0.09 \\
\hline
\end{tabular}

*Case 1: Reducing the policy variable values of RJ by $5 \%$

$* *$ Case 2 : Increasing the policy variable values of TN by $5 \%$

\subsection{Captive/Third party utilization feasibility and repowering policy}

A feasibility of the captive use in these states is beneficial for the project developers as they have freedom to transmit the excess generated power to other states. The captive utilization facility allows the power developers to generate power at one place and utilize, sell or purchase to and from the other distant place through the grid. The captive utilization of the generated power is feasible only in three of the considered seven states (KA, GJ and TN) (Table 12). The provision for the captive utilization facility is due to the higher level of wind power potential in these states. The remaining four states (MH, RJ, MP and AP) are not providing the captive facility as they are willing to use the entire generated power within the states due to the lower wind power potential and to meet the overall demand of electricity.

Repowering is the procedure of substituting or supplementing existing power plants through newer projects that have a higher nameplate capacity or superior efficiency, which leads to a boost in power generation. Only, four states of India (MH, GJ, TN and AP) have the repowering policy for wind power projects (Table 12). The availability of repowering policy makes these states more preferable over other states, as they allow project developers to upgrade the existing power projects and additional capacity installation.

\subsection{Wind energy technologies and available power potential}

The assessment of wind power potential prior to the project establishment is very important [42]-[44]. India have the total wind power potential $302.25 \mathrm{GW}$ ) [33]. GJ and TN have the total onshore wind power potential of $84.43 \mathrm{GW}$ and $33.80 \mathrm{GW}$, respectively. TN and GJ are the leading states of India in terms of installed capacity of $7870 \mathrm{MW}$ and $5613 \mathrm{MW}$, respectively. However, these capacities are only $23.28 \%(\mathrm{TN})$ and $6.65 \%(\mathrm{GJ})$ of their actual potential (Table 9). This scenario indicates that "the fraction of power potential that has been converted to installed capacity" is also a very crucial parameter. Moreover, there is no offshore wind power generation project in India; hence, the mentioned installed capacity corresponds to the onshore projects. In order to address this matter, National Institute of Wind Energy (NIWE) has identified eight favorable offshore locations near the coast of Gujarat and Tamil Nadu and planning to establish India's first offshore wind Power project [45]. Based on the addition of the offshore wind potential, the RPO targets have not been updated yet. However, the national wind power generation targets are well specified for the onshore and offshore wind power i.e. $60 \mathrm{GW}$ from onshore and $5 \mathrm{GW}$ offshore wind power sector to be achieved by 2022 [8], [9]. At present, the wind energy policies are equally applicable to all 
kinds of wind turbines i.e. vertical axis wind turbine (VAWT) and horizontal axis wind turbine (HAWT). There are some innovative performance enhancement systems such as Invelox and Funnel type wind power generators [46] are yet to be explored in India due to the absence of system specific policies for deployment.

In India, the period of allotment to the sub-station capacity is decided based on the scale of the project. Larger capacity plant gets allotment for longer duration [47]. The project of $1-$ 100 MW capacity gets 1.5 years entitlement from the date of transmission capacity allotment; and additional time for higher capacities, e.g. 2, 3 and 4 years for 101-200 MW, 201$400 \mathrm{MW}$ and 401-600 MW capacities, respectively [47]. Moreover, the technology for the power project is selected based on the local wind characteristics, i.e. wind class, which is defined by local wind power density and wind speed values (Table 10). It is now feasible to extract energy from lower power density regions due to the technological advancements and the permissions of low capacity power projects. However, the small scale retail wind power generation has not been supported by the present policy provisions.

Furthermore, the declaration of wind-solar hybrid policy has opened the scope of repowering and hybridization of wind and solar power projects [8]. The hybridization of projects have direct positive impacts on the cost of the electricity generation i.e. Levelized cost, as the same portion of land is being utilized by both the power generation and the adjoined electrical systems. The output total harmonic distortion of wind-solar hybrid system has been reportedly curtailed due to a newly introduced switching method, which leads to more stable and less fluctuating power output [48]. The feasibility to connect multiple renewable power sources i.e. wind power system, micro-wind turbines, photovoltaic panels etc. to the electrical grid has also been presented in recent studies [48], [49]. Thus, the declaration of the supportive and resource optimizing policies with recent technological advancements in wind power have a remarkable impact on the growth of renewable power generation.

Due to technological advancements, the nameplate installed capacity of wind turbines in India has increased with an annual growth rate of $3 \%$ since 2012 , with current value of 2.3 MW [50]. This has happened due to the development of higher rotor diameters, higher hub heights and advanced airfoil sections of turbine blades [51]. The average wind turbine blade length was $42 \mathrm{~m}$ in 2010 which has now increased to $58 \mathrm{~m}$; and projected to reach $60 \mathrm{~m}$ in 2022 [51]. Hence, the practical CUF of wind turbines has reached to an exceptional level of $40 \%$ [52]. The Indian wind Atlas prepared by NIWE had identified the wind power CUF range of 20-28\% in 2015 [53]. In India, the wind and solar power tariff rates are uniformly decided based on the CUF of $24.5 \%$ and $19 \%$, respectively. However, the recent wind and solar power projects in India have attained the CUF over $35 \%$ and $25 \%$, respectively [52]. This gap between the actual CUF values achieved and the tariff defining CUF value indicates lack of synchronization between government policymakers and the project developers. Moreover, the value of CUF directly influences the Levelized Cost of Electricity (LCOE) [54]. Higher CUF value leads to lower LCOE value which allows project developers to sell power at lower tariff rates [15]. 
TABLE 9. INDiAn StATUS OF Wind ENERGY (MW) [14], [55], [56]

\begin{tabular}{llllllll}
\hline State & $\begin{array}{l}\text { Installed } \\
\text { capacity } \\
(\mathbf{M W})\end{array}$ & $\begin{array}{l}\text { Power } \\
\text { potential } \\
\text { @ 100m } \\
(\mathbf{M W})\end{array}$ & $\begin{array}{l}\text { Ratio of } \\
\text { installed } \\
\text { capacity to } \\
\text { potential }\end{array}$ & $\begin{array}{l}\text { PCNDP } \\
(\mathbf{₹})\end{array}$ & $\begin{array}{l}\text { Power } \\
\text { generation - } \\
\text { Surplus (+ve) } \\
\text { / Deficit } \\
(-\mathbf{v e}) \mathbf{\%}\end{array}$ & $\begin{array}{l}\text { Wind power } \\
\text { generation, } \\
\text { GWh }\end{array}$ & $\begin{array}{l}\text { Emission } \\
\text { reduction } \\
\text { (megaton } \\
\text { of CO }\end{array}$ \\
\hline MH & 4752 & 45394 & 0.1047 & 117285 & 7.4 & 8326 & 7.88 \\
KA & 3774 & 55854 & 0.0676 & 117988 & 4.6 & 6612 & 6.26 \\
GJ & 5613 & 84431 & 0.0665 & 113229 & 4.2 & 9834 & 9.31 \\
RJ & 4282 & 18770 & 0.2281 & 66989 & -0.2 & 7502 & 7.10 \\
TN & 7870 & 33799 & 0.2328 & 157116 & -3.3 & 13788 & 13.06 \\
MP & 2497 & 10483 & 0.2382 & 54416 & 11.9 & 4375 & 4.14 \\
AP & 3610 & 44228 & 0.0816 & 92730 & -7.6 & 6325 & 5.99 \\
\hline Total & $\mathbf{3 2 2 1 4}$ & $\mathbf{2 9 2 9 5 9}$ & - & $\mathbf{7 1 9 7 5 3}$ & - & $\mathbf{5 6 4 3 9}$ & $\mathbf{5 3 . 4 5}$ \\
\hline
\end{tabular}

TABLE 10. Wind Class CORRESPONDING to Wind POWER DENSITY AND WIND SPEED FOR 100 M HUB HEIGHT [57]

\begin{tabular}{lll}
\hline Wind Class & $\begin{array}{l}\text { Wind Power Density } \\
\left(\mathbf{W} / \mathbf{m}^{2}\right)\end{array}$ & $\begin{array}{l}\text { Wind Speed (WS) } \\
(\mathbf{m} / \mathbf{s})\end{array}$ \\
\hline I & $<260$ & $<6.1$ \\
II & $260-420$ & $6.1-7.1$ \\
III & $420-560$ & $7.1-7.8$ \\
IV & $560-670$ & $7.8-8.3$ \\
V & $670-820$ & $8.3-8.9$ \\
VI & $820-1060$ & $8.9-9.7$ \\
VII & $>1060$ & $>9.7$ \\
\hline
\end{tabular}

\subsection{Other possible influential factors}

Energy generation and the condition power sector is highly interactive with economic, social and environmental aspects [58]. Therefore, along with the policy scenario, other state-specific factors that might affect the growth of power generation like wind power installed capacity, power potential, per capita net domestic product (PCNDP) and status of overall power generation (surplus/deficiency) are considered for the study (See Fig. 3 and Table 9). PCNDP indicates net domestic product of the state per capita, which signifies the economic growth of the state. Higher value of PCNDP indicate favorable financial scenario and vice versa. For the considered states, PCNDP value varies from ₹66 989 (for RJ) to ₹157 116 (for TN). The surplus/deficiency scenario indicates the amount of total power generation in the state with reference to total electricity demand of that state. Here, the positive values indicate that the amount of power generation is higher than the demand and vice versa. For the considered states this value varies from $-7.6 \%$ (AP) to $11.9 \%$ (for MP). Further, Table 11 contains the Spearman correlation coefficient matrix. The lower values of the correlation coefficient for all three combinations indicate that the considered three variables are independent and do not affect each other. This signifies that the PCNDP and power generation-demand relation do not influence the growth of wind power generation in all the considered states as both the factors are completely independent to the ratio of installed 
capacity to the potential. However, the $p$-values $(>0.05$ in Table 12) indicate that these results are not significant and may vary with time and scenario, therefore these factor are not discussed further.

TABLE 11. SPEARMAN CORRELATION COEFFICIENT FOR THE CONSIDERED AUXILIARY DECISIVE FACTORS

\begin{tabular}{llll}
\hline & $\begin{array}{l}\text { Ratio of installed } \\
\text { capacity to potential }\end{array}$ & PCNDP & $\begin{array}{l}\text { Power surplus / } \\
\text { deficit }\end{array}$ \\
\hline $\begin{array}{l}\text { Ratio of installed } \\
\text { capacity to potential }\end{array}$ & 1.00 & & \\
& $(0.00)$ & 1.00 & \\
\cline { 2 - 4 } PCNDP & -0.29 & $(0.00)$ & \\
& $(0.54)$ & -0.21 & 1.00 \\
Power surplus / deficit & 0.18 & $(0.65)$ & $(0.00)$ \\
\hline
\end{tabular}

Note: The figures in parenthesis indicate $p$-values (probability values).

\section{DISCUSSION}

The overall scenario of the state-wise factors regarding the wind power development in respective states is presented in Table 12. Rajasthan has the highest policy index of 2.4423, which implies that the state government provides a better policy environment in order to tackle the low wind power potential. However, due the lowest CUF of $24.4 \%$, the non-availability of captive utilization feasibility and the absence of repowering policy, RJ has considerably lower cumulative installed capacity of $4282 \mathrm{MW}$. MH and KA have relatively higher policy index of 0.026 and 0.31 , respectively, and these states have also a relatively higher potential (45.39 GW in $\mathrm{MH}$ and $55.85 \mathrm{GW}$ in KA). Maharashtra has captive use allowance, but no repowering policy; whereas Karnataka has the repowering policy, but the captive use is not allowed. Moderate CUF over $26 \%$ and the payment delay of less than 9 months makes these states a reliable location for the establishment of wind power projects. The lower policy index of -0.4012 has been obtained for Madhya Pradesh. The state has the lowest wind power potential $(10.48 \mathrm{GW})$ among the considered states; and it does not allow captive/third party utilization and repowering. Such scenario makes it comparatively less desirable to attract investors for wind power project deployment.

GJ, AP and TN exhibit negative policy indices as $-0.3418,-0.8994$ and -1.1430 , respectively. However, these states have higher wind power potential of $84.43 \mathrm{GW}(\mathrm{GJ})$, 44.23 GW (AP) and $33.80 \mathrm{GW}(\mathrm{TN})$. Moreover, the provision for a captive/third party use and the presence of repowering policy make GJ and TN preferable states over other considered states. Here, it is worthwhile to mention that the actual CUF obtained in GJ ranges from $29.94 \%$ to $41.68 \%$, which is exceptionally higher than that of other states of India (Table 13). Such higher CUF in GJ is due to the utmost power potential of $84.43 \mathrm{GW}$. Further, GJ is the only state in India providing on-time payments to the projects developers. Hence, due to these facts, GJ is the most preferable location for the establishment of wind power projects, which is reflected in its significant cumulative installed capacity of $5.61 \mathrm{GW}$.

Here, it can be concluded that the aggregate policy indices, captive/third party use feasibility, presence of repowering policy, actual CUF obtained at the location, delay in cash flow and total available power potential are the factors that significantly influence the growth 
of cumulative installed capacity. GJ and TN have exhibited noteworthy growth of wind power in spite of negative aggregate policy index due to the higher CUF, feasibility of captive use and presence of repowering policy (Table 12). Hence, the effect of feasibility of captive/third party utilization, the repowering policy, wind power potential and the actual capacity utilization factor are significant on wind power deployment as compared to policy parameters (FIT rate, PPA duration, RPO target).

Moreover, India has started to decide the tariff rates based on the reverse auction since 2017 [22], which encompasses the consideration of all the above discussed influential parameters. Consequently, this has led to a highly competitive FIT rate. Further, The FIT rate ranges from ₹4.16/kWh $(\$ 0.06 / \mathrm{kWh})$ to $₹ 5.74 / \mathrm{kWh}(\$ 0.083 / \mathrm{kWh})$ in different states of India. The reverse auction based procedure is governed by the Solar Energy Corporation of India Limited (SECI) which decides the maximum tariff limit for a project and accordingly advertises a Request for Selection (RfS) proposal. Project developers submit their bids as per their Levelized cost of the projects and SECI approves the tender with the lowest tariff. The impact of bidding process has severely reduced the tariff rates and created a strong competitive environment among the project developers. This process has reduced the profit margin of the project developers and demotivated them either to reduce the quality or cut-off the research costs, and either way is harmful on the long term scale. Therefore, India should consider reintroducing the FIT rate based system by considering the regional and global aspect affecting wind projects with higher tariffs.

Additionally, every unit MWh electricity generation through wind energy sources leads to a reduction of 0.947 ton of $\mathrm{CO}_{2}$ emission [59], [60]. Hence, the deployment of wind power generation leads to the emission reduction. Thus, the acceleration of wind power deployment would help to meet the emission reduction targets as per the agreement of COP21 summit. Currently TN and GJ are leading the annual $\mathrm{CO}_{2}$ emission reduction of 13.06 and 9.31 megaton, respectively. The states $\mathrm{MH}, \mathrm{KA}$ and $\mathrm{RJ}$ also have $\mathrm{CO}_{2}$ emission reduction rate above 6 megaton/year, whereas $\mathrm{MP}$ and $\mathrm{AP}$ have the $\mathrm{CO}_{2}$ emission drop below 6 megaton/year from wind power generation.

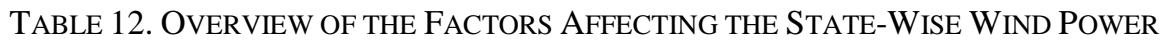 DEPLOYMENT}

\begin{tabular}{llllll}
\hline State & $\begin{array}{l}\text { Aggregate } \\
\text { policy index }\end{array}$ & $\begin{array}{l}\text { Captive /Third } \\
\text { Party Use } \\
\text { feasibility }\end{array}$ & $\begin{array}{l}\text { Repowering } \\
\text { policy }\end{array}$ & $\begin{array}{l}\text { CUF (Actual), } \\
\%\end{array}$ & $\begin{array}{l}\text { Terms of payment to } \\
\text { developers }\end{array}$ \\
\hline MH & 0.0260 & No & Yes & 26.66 & 6 months delay \\
KA & 0.3170 & Yes & No & $27.75-29.12$ & $7-9$ months delay \\
GJ & -0.3418 & Yes & Yes & $29.94-41.68$ & On time \\
RJ & 2.4423 & No & No & 24.40 & 6 months delay \\
TN & -1.1430 & Yes & Yes & 29.29 & $9-12$ months delay \\
MP & -0.4012 & No & No & 28.47 & $7-9$ months delay \\
AP & -0.8994 & No & Yes & 27.48 & 9 months delay \\
\hline
\end{tabular}

\section{CONClusion}

From the present work, it can be concluded that state wind power policies play an important role in the deployment of wind power generation in the selected wind prone states. The state 
policies data of FIT, PPA duration and RPO are taken as input to derive the aggregate policy indices for each respective state using multivariate statistical analysis. FIT has a nominal correlation with PPA duration and RPO target. However, PPA duration and RPO policies are highly correlated with each other having the correlation coefficient of -0.84 .

At present, the wind energy policies are independent of the type of wind turbine technology. Therefore, recently developed innovative wind machines are yet to be explored in India due to the absence of wind machine specific policies for deployment. However, it is now feasible to extract energy from lower power density regions due to the technological developments and the provision in policies for the permission of low capacity power projects. It has been observed that the small scale retail wind power generation has not been supported by the present policy provisions.

It is expected that the recently declared supportive and resource optimizing hybrid policy with recent grid related technological advancements in wind power will have a remarkable impact on the growth of renewable power generation. Further, recently achieved Higher CUF values (around $40 \%$ ) will lead to a lower LCOE value which allows project developers to sell power at lower tariff rates. Other influential factors like PCNDP and the power generation extent with reference to energy demand do not have an apparent direct impact on the growth of wind power generation. It can be concluded that the growth of wind power in a state is dependent on policy variables (FIT, PPA duration and RPO target), captive/third party utilization feasibility, presence of repowering policy, actual CUF obtained in the state and the terms of financial cash flow. The outcome of present study is useful to the policy-makers to evaluate the impact of existing policies for growth of wind power deployment and to assist the project developers to compare and identify suitable locations for new wind projects. It is recommended that the state-level policy framework should be structured in such a way that it should be mutually beneficial for the project developers as well as the government.

\section{REFERENCES}

[1] Rozentale L., Blumberga D. Methods to Evaluate Electricity Policy from Climate Perspective. Environmental and Climate Technologies 2019:23(2):131-47. https://doi.org/10.2478/rtuect-2019-0060

[2] Jekabsone A., Kamenders A., Rosa M., Kaselofsky J., Schule R. Assessment of the Implementation of Sustainable Energy Action Plans at Local Level. Case Study of Latvia. Environmental and Climate Technologies 2019:23(2):3646. https://doi.org/10.2478/rtuect-2019-0053

[3] Conference of Parties (COP21). Paris, France, 2015. [Online]. [Accessed July 2, 2018]. Available: https://www.gouvernement.fr/en/cop21

[4] United Nations Climate Change 2018. [Online]. [Accessed July 2, 2018]. Available: https://unfccc.int/process-andmeetings/conferences/un-climate-change-conference-november-2017/sessions-of-negotiating-bodies/cop-23

[5] Jani H. K., Modi K. V. A review on numerous means of enhancing heat transfer rate in solar-thermal based desalination devices. Renewable and Sustainable Energy Reviews 2018:93:302-17. https://doi.org/10.1016/j.rser.2018.05.023

[6] Jani H. K, Modi K. V. Experimental performance evaluation of single basin dual slope solar still with circular and square cross-sectional hollow fins. Solar Energy 2019:179:186-194. https://doi.org/10.1016/j.solener.2018.12.054

[7] Jani H. K, Modi K. V. Techniques of improving rate of heat transfer in Solar Still as a Solar-Thermal Desalination device - A Review. International Journal of Advance Research and Innovative Ideas in Education 2017:3:2395-6.

[8] Jethani J. K. Ministry of New and Renewable Energy (MNRE) - National Wind-Solar Hybrid Policy, 2018. Available: https://mnre.gov.in/sites/default/files/webform/notices/National-Wind-Solar-Hybrid-Policy.pdf

[9] Panda B. K. Ministry of New and Renewable Energy (MNRE) - National Offshore Wind Energy Targets - June, 20, 2018. Available: https://mnre.gov.in/sites/default/files/webform/notices/New Doc 2018-06-28.pdf

[10] Shrimali G., Srinivasan S., Goel S., Nelson D. The effectiveness of federal renewable policies in India. Renewable and Sustainable Energy Reviews 2017:70:538-550. https://doi.org/10.1016/j.rser.2016.10.075

[11] Lin B., Zhu J. Is the implementation of energy saving and emission reduction policy really effective in Chinese cities? A policy evaluation perspective. Journal of Cleaner Production 2019:220:1111-1120. https://doi.org/10.1016/j.jclepro.2019.02.209 
[12] The Electricity Act 2003 (No. 36 of 2003) Government of India (Ministry of Law and Justice). New Delhi, 2003. Available: http://www.cercind.gov.in/Act-with-amendment.pdf

[13] National Electricity Policy 2005 (No. 23/40/2004-R\&R Vol. II) Government of India (Ministry of Power). New Delhi, 2005. Available: http://www.lse.ac.uk/GranthamInstitute/wp-content/uploads/laws/1324.pdf

[14] Panse R., Kathuria V. Role of policy in deployment of wind energy: Evidence across states of India. Renewable and Sustainable Energy Reviews 2016:53:422-432. https://doi.org/10.1016/j.rser.2015.08.056

[15] Shrimali G., Nelson D., Goel S., Konda C., Kumar R. Renewable deployment in India: Financing costs and implications for policy. Energy Policy 2013:62:28-43. https://doi.org/10.1016/j.enpol.2013.07.071

[16] Assessment of Investment Climate for Wind Power Development in India. Indian Renewable Energy Agency (IREDA), September 2011. Available: http://www.ireda.in/writereaddata/Assessment.pdf

[17] Operational Guidelines For AD Policy For Wind 2014. Indian Renewable Energy Agency (IREDA), 2014. Available: http://www.ireda.in/writereaddata/OPERATIONAL\%20GUIDELINES\%20FOR\%20AD(1).pdf

[18] Operational Guidelines For GBI For Wind. Indian Renewable Energy Agency (IREDA), 2015. Available: http://www.ireda.in/writereaddata/Operational Guidelines.pdf

[19] Upadhyay G. National Offshore Wind Energy Policy 2015 - Ministry of New and Renewable Energy (MNRE), 2015. Available: http://mnre.gov.in/file-manager/UserFiles/National-Offshore-Wind-Energy-Policy.pdf

[20] Jethani J. K. National Wind-Solar Hybrid Policy 2016 - Draft - Ministry of New and Renewable Energy (MNRE), 2016. Available: http://mnre.gov.in/file-manager/UserFiles/Draft-Wind-Solar-Hybrid-Policy.pdf

[21] Jethani J. K. Scheme for setting up of 1000 MW ISTS-connected Wind power projects - Ministry of New and Renewable Energy (MNRE), 2017. Available: https://mnre.gov.in/sites/default/files/schemes/Scheme-1000MWISTS-Wind-project.pdf

[22] Prasad S. Guideline for Tariff based Bidding Process for Wind Power Projects - Ministry of Power (MOP), 2017. Available: https://mnre.gov.in/file-manager/UserFiles/guideline-wind.pdf

[23] Naik S. Tariff Policy 2018. Draft. Proposed Amendments. Ministry of Power (MOP), 2018. Available: https://powermin.nic.in/sites/default/files/webform/notices/Proposed_amendments_in_Tariff_Policy.pdf

[24] IRENA (International Renewable Energy Agency). Wind Energy Data. 2019. [Online]. [Accessed July 2, 2018]. Available: http://www.irena.org/wind

[25] Renewable electricity generation in India. 2019. Available: https://en.wikipedia.org/wiki/Renewable_energy_in_India

[26] Pathak L., Shah K. Renewable energy resources, policies and gaps in BRICS countries and the global impact. Frontiers in Energy 2019:13:506-521. https://doi.org/10.1007/s11708-018-0601-Z

[27] Jagadeesh A. Wind energy development in Tamil Nadu and Andhra Pradesh, India institutional dynamics and barriers -A case study. Energy Policy 2000:28(3):157-168. https://doi.org/10.1016/S0301-4215(00)00007-0

[28] Benecke G. "CDM - So What?": Analysing Determinants of Private Sector Participation in Renewable Energy Deployment in India. Global Environmental Change Human and Policy Dimensions. Long-Term Governance for. Socio-Ecological Change. Berlin, 2008. [Online]. [Accessed July 2, 2018]. Available: http://citeseerx.ist.psu.edu/viewdoc/download;jsessionid=46A2AF56EBF5B617B8A646DAC14E2DA8?doi=10.1.1. $556.8286 \&$ rep=rep $1 \&$ type $=$ pdf

[29] Usha Rao K., Kishore V. V. N. Wind power technology diffusion analysis in selected states of India. Renewable Energy 2009:34(4):983-988. https://doi.org/10.1016/j.renene.2008.08.013

[30] Schmid G. The development of renewable energy power in India: Which policies have been effective? Energy Policy 2012:45:317-326. https://doi.org/10.1016/j.enpol.2012.02.039

[31] Kathuria V., Ray P., Bhangaonkar R. FDI (foreign direct investment) in wind energy sector in India: Testing the effectiveness of state policies using panel data. Energy 2015:80:190-202. https://doi.org/10.1016/j.energy.2014.11.062

[32] Sangroya D., Nayak J. Effectiveness of state incentives for promoting wind energy: A panel data examination. Frontiers in Energy 2015:9:247-258. https://doi.org/10.1007/s11708-015-0364-8

[33] Jethani J. K. Wind Power Development in India. Akshay Urja Report. August-October 2017. Available: https://mnre.gov.in/file-manager/akshay-urja/october-2017/Images/20-25.pdf

[34] Count Data Models. Econometrics Academy. [Online]. [Accessed: August 7, 2019]. Available: https://sites.google.com/site/econometricsacademy/econometrics-models/count-data-models

[35] Lin B., Chen Y. Impacts of policies on innovation in wind power technologies in China. Applied Energy 2019:247:682691. https://doi.org/10.1016/j.apenergy.2019.04.044

[36] Lever J., Krzywinski M., Altman N. Points of Significance: Principal component analysis. Nature Methods 2017:14:641-642. https://doi.org/10.1038/nmeth.4346

[37] Aboltins R., Blumberga D. Key Factors for Successful Implementation of Energy Efficiency Policy Instruments: A Theoretical Study and the Case of Latvia. Environmental and Climate Technologies 2019:23(2):187-206. https://doi.org/10.2478/rtuect-2019-0063

[38] Spearman Rank Correlation (Spearman's Rho): Definition and How to Calculate it n.d. [Online]. [Accessed September 19, 2018]. Available: http://www.statisticshowto.com/spearman-rank-correlation-definition-calculate/

[39] Introduction to Principal Components and Factor Analysis 2007. [Online], [Accessed September 10, 2018]. Available: ftp://statgen.ncsu.edu/pub/thorne/molevoclass/AtchleyOct19.pdf 
[40] Weisstein E. W. Eigenvalue and Eigenvectors n.d. [Online]. [Accessed: September 27, 2018]. Available: http://mathworld.wolfram.com/Eigenvalue.html

[41] NCSS, NCSS Statistical Software -Principal Components Analysis. [Assessed: September 10, 2018] https://ncsswpengine.netdna-ssl.com/wp-content/themes/ncss/pdf/Procedures/NCSS/Principal_Components_Analysis.pdf

[42] Jani H. K, Nagababu G., Patel R. P., Kachhwaha S. S. A Comparative Analysis of LiDAR and Wind Mast Measured Wind Data with the Reanalysis Datasets for an Offshore Location of Gujarat. In: Vijayaraghavan L., Reddy K., Jameel Basha S., editors. Emerging Trends in Mechanical Engineering. Lecture Notes in Mechanical Engineering. Singapore. Springer 2020:627-634. https://doi.org/10.1007/978-981-32-9931-3_61

[43] Jani H. K., Nagababu G., Patel R. P., Kachhwaha S. S. Comparative Study of Meteorological and Reanalysis Wind Data For offshore Wind Resource Assessment. Presented at ICTEA Int. Conf. Therm. Eng., 2019. Available: https://journals.library.ryerson.ca/index.php/ictea/article/view/1125

[44] Nagababu G. et al. Estimation of uncertainty in offshore wind energy production using Monte-Carlo approach. Presented at ICTEA Int Conf. Therm. Eng., $2019 . \quad$ Available: https://journals.library.ryerson.ca/index.php/ictea/article/view/1113

[45] Wind Resource Assessment \& Offshore Unit. - Interim Report (First offshore Lidar Wind Data Analysis). National Institute of Wind Energy (NIWE), 2018. Available: http://niwe.res.in/assets/Docu/Interim_Report-Offshore_LidarGujarat-ver-1.pdf

[46] Kumar N. M., Subathra M. S. P., Cota O. D. Design and Wind Tunnel Testing of Funnel Based Wind Energy Harvesting System. Procedia Technologies 2015:21:33-40. https://doi.org/10.1016/J.PROTCY.2015.10.006

[47] Gujarat Wind Power Policy - Government of Gujarat, Energy and Petrochemicals Department, 2016. Available: http://www.cbip.org/Policies2019/PD_07_Dec_2018_Policies/Gujarat/2Wind/2\%20Order\%20Gujarat_Wind_Power_Policy-2016.pdf

[48] Turksoy A., Hames Y., Teke A., Latran M. B. A novel adaptive switching method to reduce DC-Link capacitor ripple in PV based grid-connected inverter. Solar Energy 2018:173:702-714. https://doi.org/10.1016/j.solener.2018.08.002

[49] Inci M., Turksoy O. Review of fuel cells to grid interface: Configurations, technical challenges and trends. Journal of Cleaner Production 2019:213:1353-1370. https://doi.org/10.1016/j.jclepro.2018.12.281

[50] Deign J. An Illustrated Guide to the Growing Size of Wind Turbines Greentech Media 2017. [Online]. [Accessed August 13, 2019]. Available: https://www.greentechmedia.com/articles/read/an-illustrated-guide-to-the-growing-sizeof-wind-turbines\#gs.vzth79

[51] Li A. Global Wind Turbine Technology Trends. Japan offshore wind market overview. MAKE, 2017. http://www.indianwindpower.com/pdf/windergy/April-26th/Mr-Bo-li-Innovation.pdf

[52] Renewable Energy Certificate Mechanism in India - Key learning, data analysis and way forward. Power System $\begin{array}{llll}\text { Operation } & \text { Corporation } & \text { Limited } & \text { (POSOCO), }\end{array}$ https://recregistryindia.nic.in/pdf/Others/Report_on_REC_Mechanism.pdf

[53] Gujarat Electricity Regulatory Commission (GERC). Order no. 3 of 2015. Determination of tariff for Solar Energy Projects, 2015. Available: https://geda.gujarat.gov.in/policy_files/GERC_order_no._3_of_2015.pdf

[54] Das A., Jani H. K., Nagababu G., Kachhwaha S. S. Influence of Techno-Economic Factors on the Levelized Cost of Electricity (LCOE) of Wind and Solar Power Projects in India. Presented at ICTEA Int. Conf. Therm. Eng., 2019. Available: https://journals.library.ryerson.ca/index.php/ictea/article/view/1116

[55] Tiers of Government - Reserve Bank of India. Per Capita Net State Domestic Product at Factor Cost (Current Prices) - Datasets - Open Budgets India n.d. [Online]. [Accessed August 10, 2018]. Available: https://openbudgetsindia.org/dataset/per-capita-net-state-domestic-product-at-factor-cost-current-prices

[56] Dubey S. D. Power Deficiency of states of India. Central Electricity Authority (CEA), Ministry of Power (MOP), 2016. Available: http://www.cea.nic.in/reports/annual/lgbr/lgbr-2016.pdf

[57] Oh K. Y., Kim J. Y., Lee J. K., Ryu M. S., Lee J. S. An assessment of wind energy potential at the demonstration offshore wind farm in Korea. Energy 2012:46(1):555-563. https://doi.org/10.1016/j.energy.2012.07.056

[58] Deenapanray P. N. K., Bassi A. M. System dynamics modelling of the power sector in mauritius. Environmental and Climate Technologies 2015:16(1):20-35. https://doi.org/10.1515/rtuect-2015-0010

[59] Ministry of Power. Government of India. $\mathrm{CO}_{2}$ Baseline Database for the Indian Power Sector User Guide, 2014. Available: http://cea.nic.in/reports/others/thermal/tpece/cdm_co2/user_guide_ver9.pdf

[60] Ministry of Power. Government of India. $\mathrm{CO}_{2}$ Baseline Database for the Indian Power Sector User Guide, 2018. Available: http://cea.nic.in/reports/others/thermal/tpece/cdm_co2/user_guide_ver13.pdf 

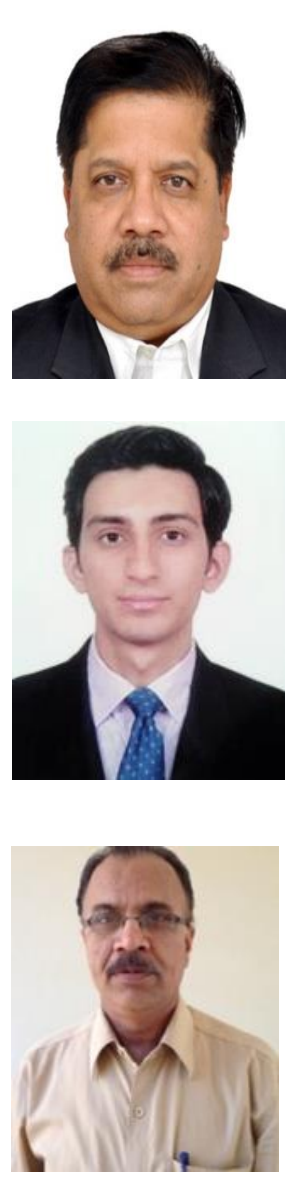

Dr Surendra Singh Kachhwaha completed a BE degree in Mechanical Engineering from M. B. M. Engineering College, Jodhpur. He did the M.Tech. in Heat Power from Indian Institute of Technology, BHU Varanasi and PhD in Evaporative Cooling from IIT Delhi. He has taught various thermal engineering courses at undergraduate and post graduate level and guided thirty M. Tech Dissertation and five PhDs. Chair Professor Suzlon in Mechanical Engineering Dept, School of Technology, Pandit Deendayal Petroleum University, Gandhinagar. A co-author of sixty technical publications in reputed national and international journals and more than 70 publications in national/international conferences.

ORCID iD: https://orcid.org/0000-0001-7497-6258

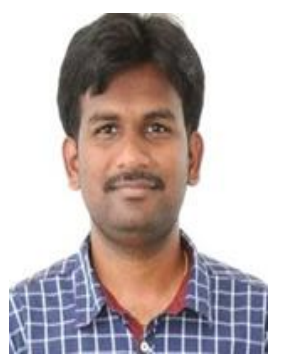

Dr Garlapati Nagababu is presently working as an assistant professor in the mechanical engineering department, PDPU, Gandhinagar since 2013. He completed the $\mathrm{PhD}$ in the field of offshore wind energy and M.Tech. from IIT Guwahati in machine design specialization. Dr. Nagababu has more than 7 years teaching experience in the field of mechanical engineering at UG and PG level. His research mainly focuses on offshore renewable energy resource assessment, development of small-scale wind turbine and hybrid energy system. He has published the number of research articles in highly reputed journals and international conferences in the field of energy. He is currently working on different projects funded by ISRO and ORSP. ORCID iD: https://orcid.org/0000-0003-3718-271X 